\title{
ENHANCING ASSET MANAGEMENT THROUGH A BETTER UNDERSTANDING OF ENERGY CONSUMPTION
}

\author{
James S. GRIFFIN a, Alfred E. THAL, Jr. ${ }^{\text {a,* }}$, Sonia E. LEACH ${ }^{\text {b }}$ \\ a Air Force Institute of Technology, Graduate School of Engineering and Management, Wright-Patterson \\ Air Force Base, 2950 Hobson Way, Ohio 45433-7765, USA \\ ${ }^{b}$ University of Texas at Dallas Richardson, Texas 75080, USA
}

Received 8 November 2012; accepted 18 May 2013

\begin{abstract}
Asset management is a systems approach to managing an organization's portfolio of real property assets. Although a range of activities exist to help manage these assets, understanding facility energy consumption is a critical component from a life-cycle decision-making perspective. Since energy consumption is a national concern for most countries, this has resulted in various initiatives regarding energy conservation measures. To better understand the factors affecting energy consumption in facilities, energy and meteorological data covering 22 years were collected for 74 sites located throughout the world. A regression model with an adjusted $\mathrm{R}^{2}$ value of $81 \%$ was subsequently developed to predict energy consumption for each site. Additionally, using trend analysis, we found that the amount of energy used to meet heating load requirements was much greater than the amount used to meet cooling load requirements. The insight gained through the research can help facility managers develop energy initiatives as part of their overall asset management strategy.
\end{abstract}

KEYWORDS: Asset management; Energy management; Energy consumption prediction

\section{INTRODUCTION}

Many organizations, particularly those in the public sector, are finding it increasingly difficult to provide necessary services while being confronted with shrinking budgets and rising costs. To help cope with these challenges, these organizations are adopting the principles of asset management. In doing so, the emphasis is on treating built and natural resources as strategic assets and managing them as efficiently as possible. One aspect of this strategic approach is developing a better understanding of the overall energy consumption associated with an organization's portfolio of facilities. More specifically, reducing energy consumption will not only reduce costs, but it will also reduce environmental impacts and contribute to sustainability efforts.

Analyzing factors impacting energy consumption associated with facilities is a complex task which has generated numerous research efforts on varying scales, ranging from individual facili-

* Corresponding author. E-mail: al.thal@afit.edu ties to entire geographic regions or countries. In some cases, organizations rely on energy audits and building simulations to develop a better understanding of the energy being consumed in single facilities. In other cases, researchers focus on a single energy source (e.g., electricity) in a common economic sector (e.g., residential) for regions of various sizes (e.g., Eto 1988; Valor et al. 2001; Sailor, Munoz 1997; Le Comte, Warren 1981). The most notable trend observed in the existing literature was that, of all weather conditions studied, outdoor air temperature had the most significant impact on energy consumption, thus becoming the standard measure of analysis. Although this confirms what people intuitively think, non-weather related factors may also be critical in predicting energy consumption and managing facilities.

Therefore, this research examined multiple energy sources and two economic sectors (residential and commercial) associated with federal facilities owned and operated by the United States Air Force. The objective was to develop a regressionbased model that energy managers can use to gain a better understanding of energy consumption 
factors and trends from a macro perspective. The resulting insight should prove useful in reducing costs and making better asset management decisions. Although the study focused on the Air Force, each installation is analogous to a small municipality or similar entity (e.g., university campus or large corporation with geographically separated units) responsible for real property assets. Therefore, the results and insight gained through the research may be considered applicable to a broad range of organizations concerned with energy consumption and overall asset management.

\section{BACKGROUND}

Consistent with the philosophical approach used for federal entities in the United States (U.S.), asset management is concerned with the management of physical, both natural and built, real property assets. For the built environment, this includes both facilities and infrastructure. No distinction is thus made between facilities management and infrastructure management; they are both considered components of asset management. To establish a common understanding of the main topics associated with the research, this section provides background material related to asset management and energy consumption.

\subsection{Evolution of asset management}

Until the 1990s, most large organizations owning facilities, whether centralized in one location or distributed geographically, tended to focus on the operation of individual buildings (National
Resource Council 2008). However, as shown in Figure 1, the field of facilities management has undergone significant development over the past few decades (Shohet 2006). It is instructive to note that although Figure 1 is related to facilities management, the functions listed are much broader and include concepts such as utilities (i.e., infrastructure) and energy management. The inherent confusion in terminology is reflected in other terms used in the literature, to include facilities asset management, infrastructure asset management, and engineering asset management. Regardless of the term being used, the point of the figure is to illustrate that the field of facilities management has evolved. Instead of using a tactical approach, organizations now are more likely to focus on their entire portfolio of real property assets by taking a systems view and recognizing that these assets are resources that can be leveraged to help meet strategic objectives (Phelps 2011). In essence, asset management is viewed as a strategic initiative that helps organizations respond to changing needs (Okoroh et al. 2003).

Viewing real property as assets has led to the emergence of the discipline of asset management, which is still in its infancy but of growing importance (Phelps 2011). Asset management can play a critical role in transforming an organization's property from an overhead liability into a resource (Okoroh et al. 2003). Therefore, more and more organizations are recognizing that property is a cost-center that should be appropriately managed (Lavy, Shohet 2010). Therefore, an emerging theme in the literature is that asset management involves

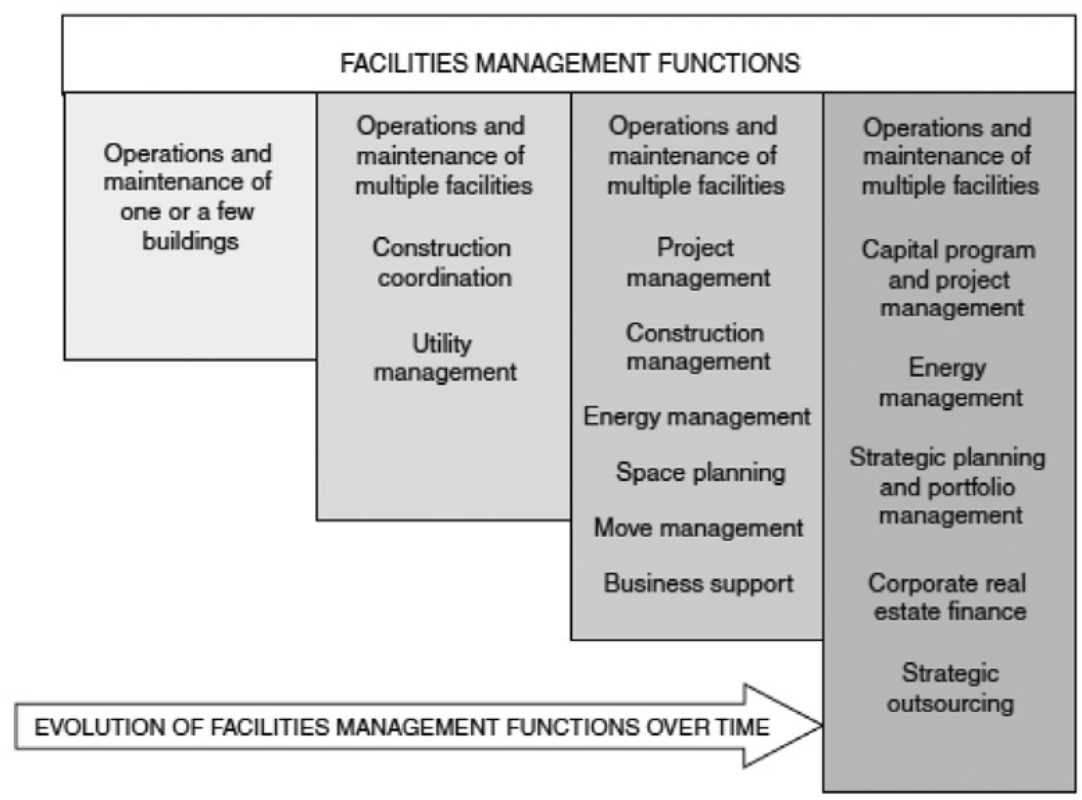

Fig. 1. Evolution of facilities management functions (National Resource Council 2008) 
business practices beyond cost-centric issues to allocate scarce resources (Price 2004; Rogers 2004). The goal is to "meet a required level of service, in the most cost-effective manner, through the management of assets for present and future customers" (Federal Highway Administration 2010). As a decision-making framework, asset management has been described as a way to help organizations "make the right investments at the right time" (Guerre et al. 2005). This broader perspective of asset management has advanced the discipline from building-specific issues to strategic resource management issues (see e.g. Then 2003).

In its most basic form, asset management can be defined as the management of physical assets, to include both facilities and infrastructure systems. With its emphasis on the entire portfolio of real property and associated costs, it can also be defined as "a systematic process of maintaining, upgrading, and operating physical assets costeffectively" in which it is viewed as a decisionmaking framework guided by performance goals (Federal Highway Administration 1999). From this perspective, the definition offered by the British Standards Institute in the form of Publicly Available Specification (PAS) 55 is more encompassing. It defines asset management as, "Systematic and coordinated activities and practices through which an organization optimally and sustainably manages its assets and asset systems, their associated performance, risks and expenditures over their lifecycles for the purpose of achieving its organizational strategic plan" (Transportation Research Board 2012).

This more inclusive approach is being used by the International Standards Organization (ISO) as the basis for development of a new ISO 55000 standard for asset management. In addition to managing assets to meet strategic objectives, the PAS 55 definition references the importance of including sustainability and trade-offs (in terms of performance, risks, and costs) in the decisionmaking process. This holistic approach facilitates both program-level and project-level management, thereby supporting both executive-level and fieldlevel decision-making (National Resource Council 2004). In the United States, it also complies with a presidential order requiring that federal agencies use "systematic analysis of expected benefits and costs ... appropriately discounted over the full lifecycle of each project" in making investment decisions (Executive Order 12893 1994).

In terms of life-cycle decision-making, typical indicators of asset performance include project completion metrics; energy, utility, or other operating costs per square foot; utilization rate; facility condition; etc. (National Resource Council 2004). Relevant to the research being reported in this paper, energy consumption throughout the world has significantly increased over the past few decades (Yu et al. 2010). The U.S. federal government thus has a significant role to play in reducing facilityrelated energy costs since it is the world's largest single owner of facilities, with a portfolio of more than 500,000 buildings (National Resource Council 2008). To support these facilities, additional real property assets include utility systems, transportation networks (roads and airfields), waste management, and the natural infrastructure. However, although the energy consumed while operating and maintaining these assets is a growing concern, the substantial costs incurred often go unchallenged (Forth, Tobin 2004). Therefore, although energy use is often directly related to the prevailing climate (Yang et al. 2011), understanding other factors which impact it could provide additional insight.

\subsection{Predicting energy consumption}

In 2010, the United States (U.S.) consumed 103.4 exajoules (EJ) of energy (DOE 2011a) compared to $550.7 \mathrm{EJ}$ for the world (DOE 2011b). Energy consumption in the U.S. thus represented $18.8 \%$ of the world's total energy consumption. By 2035, U.S. and world energy consumption are expected to increase to 120.5 and 812.1 EJ (DOE 2011b), respectively, with the U.S. proportion declining to $14.8 \%$ of the world's total. This increase in energy use is a concern since the majority of energy comes from nonrenewable sources which are not infinite. Furthermore, from an asset management perspective, the additional cost burden puts tremendous pressure on organizations to reduce energy use.

This is certainly true for public sector organizations trying to be good stewards of the taxpayers' dollars. Within the U.S. for instance, the federal government is the single largest energy consumer in the nation, using 1.2 EJ of energy in 2010 (DOE 2011a). The Department of Defense (DoD), which is one of many organizations within the U.S. federal government, utilized $80.3 \%$ of the federal government's total energy. The cost of energy used to operate and maintain DoD real property assets exceeded $\$ 4.01$ billion in 2010 , of which $\$ 1.2$ billion was for the Air Force (DoD 2011). Within the DoD, there are five primary categories of real property: administrative buildings; living quarters; special- 
Table 1. United States and DoD energy consumption by source

\begin{tabular}{llll}
\hline Energy source & Residential (DOE 2011a) & Commercial (DOE 2011a) & DoD (DoD 2011) \\
\hline Natural gas & $42.9 \%$ & $52.1 \%$ & $33.1 \%$ \\
Electricity & $42.0 \%$ & $37.6 \%$ & $43.4 \%$ \\
Coal & $0.1 \%$ & $0.7 \%$ & $7.1 \%$ \\
Petroleum/Fuel oil & $10.3 \%$ & $8.2 \%$ & $10.3 \%$ \\
Renewable & $4.7 \%$ & $1.5 \%$ & $3.0 \%$ \\
Steam & NA & NA & $2.9 \%$ \\
\hline
\end{tabular}

purpose buildings supporting operational requirements, such as aircraft hangars and training sites; and infrastructure items such as roads, water lines, etc. These categories are similar to the residential and commercial sectors included in typical statistics published by the Department of Energy (DOE). As such, Table 1 shows the consumption percentages for various energy sources in the U.S. residential and commercial sectors, along with real property energy consumption in the DoD. The key observation from this table is the heavy reliance on natural gas and electricity.

To examine these energy consumption rates, it is important to recognize that energy consumption has been correlated with various weather factors in the literature. For instance, both Lam (1998) and Yan (1998) analyzed the relationship between residential electricity consumption and weather factors in Hong Kong. Lam (1998) studied the impact of cooling degree-days, latent enthalpy days, and cooling radiation days; however, he found that cooling degree-days was the only significant factor. After adding household size, average monthly household income, and electricity price as independent variables, he used a natural logarithm transformation to arrive at $R^{2}$ values of 0.9 and 0.98 for the monthly and annual data, respectively. Yan (1998) conducted a similar study and investigated vapor pressure, cloud cover, humidity, and mean air temperature; he also included a time factor to account for economic growth and a clothing factor. He found that mean temperatures and the clothing factor were significant factors, with each providing an $\mathrm{R}^{2}$ value of 0.82 .

In a regional study, Sailor (2001) conducted an analysis of residential and commercial electricity consumption in eight geographically diverse states in the U.S.; the variables he examined were air temperature, wind speed, and humidity. The results indicated that air temperature, in the form of heating degree-days and cooling degree-days, was significant in all eight states; additionally, wind speed was significant in four states and humidity was significant in only one state. The regression equations resulted in $\mathrm{R}^{2}$ values ranging from 0.71 to 0.87 . Valor et al. (2001) conducted a similar regional study examining electricity consumption in the residential, commercial, and industrial sectors of Spain. Using elasticity demand functions, they found that the electricity load was sensitive to air temperatures. Other regional studies reported in the literature had similar results regarding the significance of air temperature (Le Comte, Warren 1981; Quayle, Diaz 1980; Mirasgedis et al. 2006). Additionally, Mirasgedis et al. (2006) found relative humidity to be a significant variable in their study. To summarize, researchers appear to be in consensus that the weather parameter with the most significant impact on energy usage is outdoor air temperature (Sailor 2001; Eto 1988; Lam 1998; Quayle, Diaz 1980; Valor et al. 2001). Other factors that have been reported in the literature include wind speed and relative humidity.

\section{METHODOLOGY}

\subsection{Data}

To limit our research effort to a manageable level, we focused on energy consumption associated with Air Force real property assets. The resulting data used in this research effort were collected from two independent sources; for both sources, the data spanned 22 consecutive years. The first source of data, consisting of energy consumption for Air Force installations, was the Air Force Civil Engineer Support Agency (AFCESA). Consumption data were categorized for the following utility sources: electricity, natural gas, fuel oil, coal, propane/liquefied petroleum gas/butane, photovoltaic, solar thermal, wind, wood, geothermal, refuse-derived, and hydroelectric power. The second source of data, consisting of weather parameters, was the Air Force Combat Climatological Center (AFCCC).

The population for our study initially consisted of 158 active duty Air Force installations. However, the following two screening criteria were used: (1) the installation must have submitted energy con- 
sumption data for the entire 22-year time period being analyzed and (2) weather data for the installation must have been available from AFCCC. After applying these two criteria, 78 installations were excluded from the study; the remaining 80 installations were widely dispersed throughout the U.S. and the world. Each of the installations is comprised of both residential and commercial sectors. However, our research focused on installation-level energy consumption associated with real property assets; therefore, the energy was aggregated at the installation level.

\subsection{Variables}

The dependent variable for the regression analysis was the facilities energy intensity (FEI), which the DoD defines as the total energy consumed per facility area. Several energy sources (e.g., electricity, fuel oil, natural gas, and coal) contribute to this variable; however, for the purposes of our study, we used the total annual energy consumption regardless of energy source. This was divided by the facility gross floor area (square meters) reported in real property records of each respective installation. The resulting units for the FEI variable were thus megajoules per square meter $\left(\mathrm{MJ} / \mathrm{m}^{2}\right)$. The quantitative independent measures included in the analysis were cooling degree-days (CDD), heating degree-days (HDD), wind speed (WS), and relative humidity $(\mathrm{RH})$ as these variables were reported in the literature as predictors of energy consumption (e.g., Eto 1988; Valor et al. 2001; Sailor, Munoz 1997; Le Comte, Warren 1981). Six independent variables were created from these quantitative measures to evaluate the interaction effects on the dependent variable; these variables were denoted as HDD*WS, HDD*RH, CDD*WS, $\mathrm{CDD}^{*} \mathrm{RH}, \mathrm{HDD}{ }^{*} \mathrm{CDD}$, and $\mathrm{WS}^{*} \mathrm{RH}$.

Three categories of qualitative independent variables were selected: headquarters, climate zone, and mission type. Each variable within these categories was coded as a dummy binary variable (0 for no and 1 for yes). The headquarters category, which represents the higher headquarters to which a given installation reports, was selected to determine if the respective headquarters influenced energy consumption at the installations. The seven headquarters units included in the study included Air Combat Command (ACC), Air Education and Training Command (AETC), Air Force Materiel Command (AFMC), Air Mobility Command (AMC), Pacific Air Forces Command (PACAF), Air Force Space Command (AFSPC), and the United States Air Forces in Europe (USAFE). The Air Force Reserve Command was not included because daily operations at these installations are not equivalent

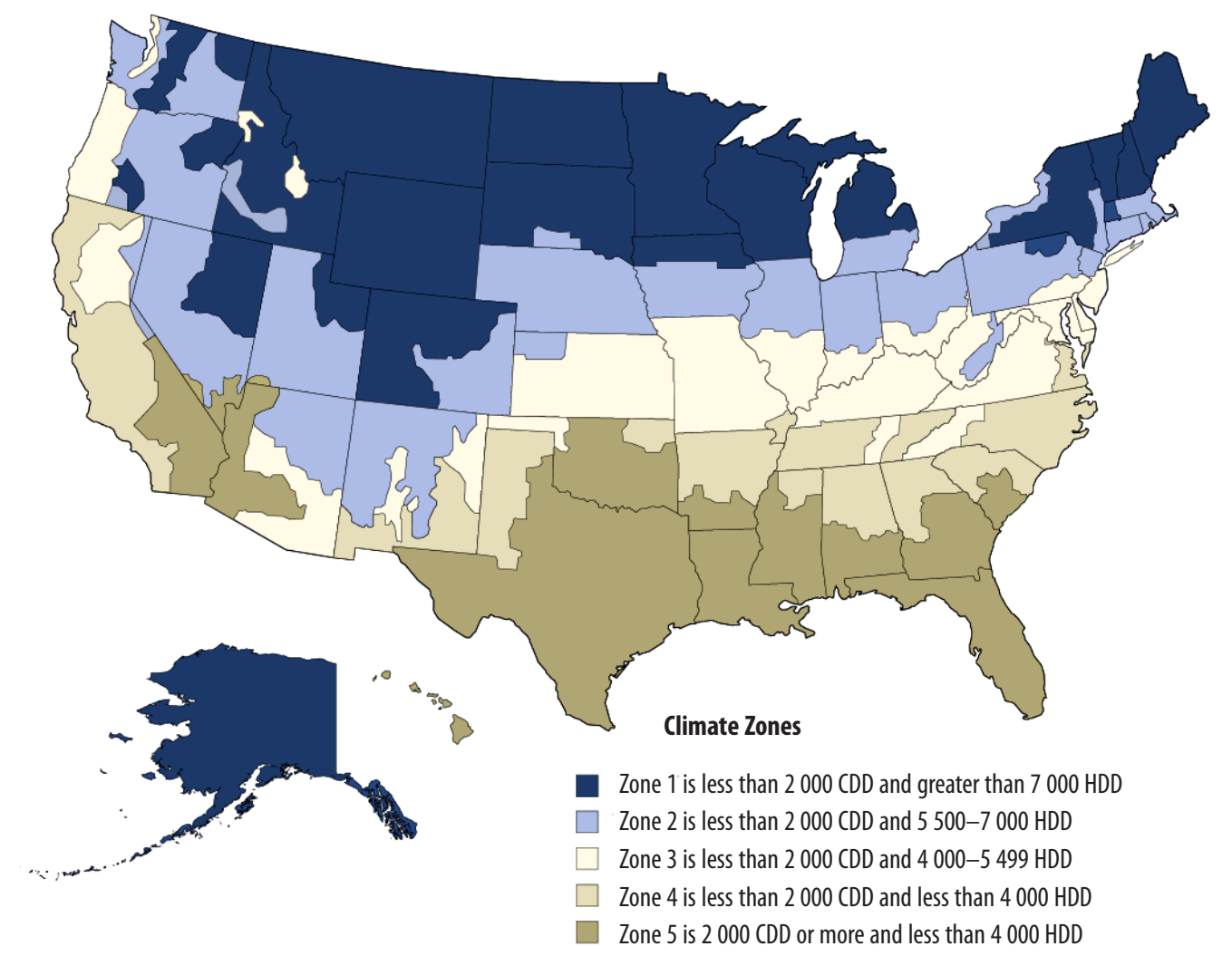

Fig. 2. Climate zones in the United States (EIA 2012) 
to those at active duty installations and adequate weather data was not readily available. The two installations assigned to the Air Force Special Operations Command were included in the ACC category based on the similarity of missions. For the analysis, ACC served as the base case and was not included in the regression model.

The next qualitative category used in the analysis represented the climate zone, as defined by the Commercial Buildings Energy Consumption Survey, in which each installation was located. The United States is thus divided into the five climate zones defined and shown in Figure 2; these zones are intended to represent similar heating and cooling load demands for facilities. Therefore, four independent variables were used to represent the climate zones in which the installations can be categorized; Climate Zone 1 served as the base case and was not included in the regression model.

Each installation was also categorized according to the primary type of mission being performed. The following four mission types were developed in a broad manner to capture the major missions at each installation without creating an excessive number of categories: Combat Flying; Non-Combat Flying; Support; and Strategic/Intelligence, Surveillance, and Reconnaissance (Strategic/ISR). Combat Flying served as the base case and was not included in the regression model. Installations classified under Combat Flying were those in which a majority of the overall mission is to conduct flying operations in which aircraft are subjected to combat missions. The Non-Combat Flying category represented installations in which flying operations occur frequently but are not subjected to combat operations; installations included in this category commonly conduct pilot training operations. The Support category represented installations that have either no flying mission or a very small flying component. A significant majority of the mission at these installations includes personnel training or research activities. Finally, installations in the Strategic/ISR category focus primarily on space launch, satellite operation and tracking, missile launch warning, space surveillance, or intercontinental ballistic missile operations.

\subsection{Analytical methods}

Regression and trend analysis were both used to examine the data. For the multivariate linear regression model, we used the six-step approach described by McClave et al. (2005). This methodology identifies the independent variables, estimates the variable regression coefficients, verifies the random error term assumptions, and evaluates the accuracy and usefulness of the model. To ensure the variables behaved in a manner conducive to linear regression, we used statistical analysis and graphical techniques to examine the data prior to analysis. For the trend analysis, we used graphical methods to determine which energy sources (electricity, natural gas, or other) varied the greatest between the heating and cooling seasons. However, since Table 1 indicates that electricity and natural gas far exceeded the remaining energy sources in terms of overall usage, only those two sources were examined.

\section{RESULTS AND DISCUSSION}

\subsection{Preliminary analysis}

Before analyzing the data, we used a histogram of the dependent variable to visually inspect the distribution of the data. The resulting histogram showed the data to be positively skewed; therefore, we used scatter plots to gain more insight into the overall behavior between the dependent variable (FEI) and each of the quantitative independent variables (HDD, CDD, WS, and $\mathrm{RH}$ ). The respective plots for wind speed and relative humility did not indicate any relationship between the variables and total energy consumption. As shown in Figure 3 though, there was an overall increase in FEI as the number of heating degree-days increased; this was expected from the results reported in the literature. However, as the number of cooling degreedays increased, there was a slight decrease in FEI as show in Figure 3. We subsequently created an additional variable which represented the sum of HDD and CDD to further investigate the relationship between the variables and FEI. The plot, which was very similar to Figure 3, indicated that HDD had a much greater influence on FEI than CDD. The HDD and CDD differences are discussed more during the trend analysis portion of the research.

The plots in Figure 3 appear to indicate the presence of outlier data points. For the HDD data, there appear to be anomalies at about 3,000 and 5,000 heating degree-days; similarly, there appeared to be anomalies at about 500 and 2,000 cooling degree-days for the CDD data. To investigate these outliers, we used a box-and-whisker plot of the dependent variable and observed that all outlier points were due to high energy consumption rates (consistent with the histogram's 

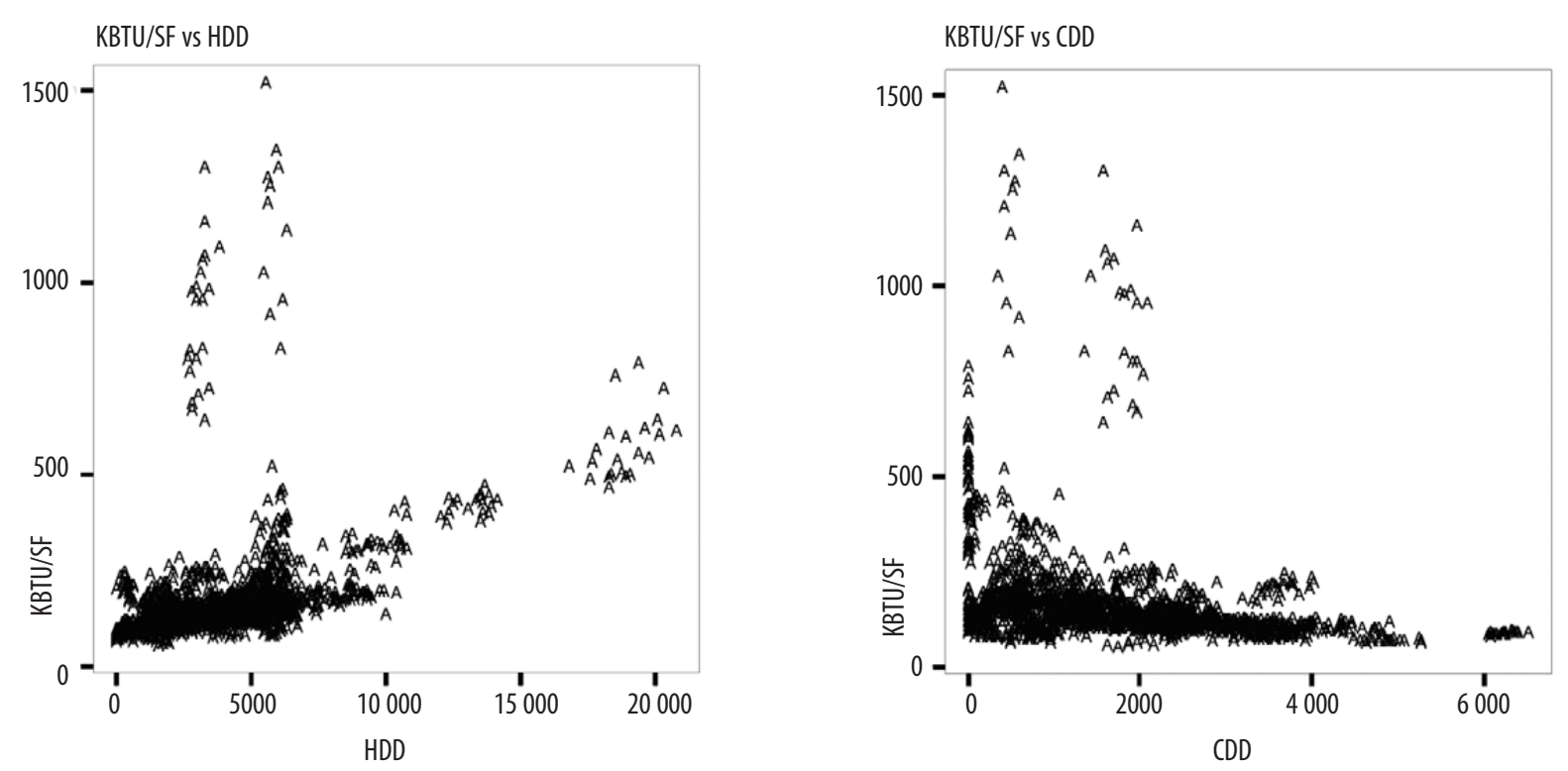

Fig. 3. Scatter plots for HDD and CDD

positive skewness). This provided an initial observation without regard to weather parameters. To incorporate weather parameters and further test for outliers, the FEI mean and standard deviation were calculated using HDD, CDD, and the summed HDD and CDD values. Six installations with outliers that exceeded \pm 2.5 standard deviations were subsequently removed from the data; this reduced the number of installations to 74 , which resulted in 1,626 data points for each variable. For each installation that was removed, there was a valid reason for its unusually high energy consumption. To test the predictive capabilities of the model, data pertaining to fiscal year 2006 were reserved and not used in the creation of the regression model. Thus, the total number of data points was reduced to 1,552 .

\subsection{Regression analysis results}

Based on the preliminary variables identified for this research, the initial regression model was of the form:

$Y=\left[\begin{array}{l}\beta_{0}+\sum_{i=1}^{4} \beta_{i} X_{i}+\sum_{i=5}^{7} \beta_{i} X_{1} X_{i-3}+\sum_{i=8}^{9} \beta_{i} X_{2} X_{i-5}+ \\ \beta_{10} X_{3} X_{4}+\sum_{i=2}^{6} \beta_{i+9} H_{i}+\sum_{i=2}^{5} \beta_{i+15} Z_{i}+\sum_{i=2}^{4} \beta_{i+19} M_{i}\end{array}\right](\mathrm{CF}),(1)$

where: $Y$ is the energy intensity $\left(\mathrm{MJ} / \mathrm{m}^{2}\right)$ for a given installation; $\beta_{i}$ are the beta coefficients; $X_{i}$ are the climate related variables (HDD, CDD, WS, and $\mathrm{RH}$, respectively); $H_{i}$ are the headquarters units (AETC, AFMC, AMC, PACAF, AFSPC, and USAFE, respectively); $Z_{i}$ are the climate zones; and $M_{i}$ are the mission categories. Since U.S. customary units were used for the variables and $Y$ was initially in thousands of BTU per square foot $\left(\mathrm{KBTU} / \mathrm{ft}^{2}\right)$, the following conversion factor (denoted as $\mathrm{CF}$ in Eq. 1) was required: $1 \mathrm{KBTU} / \mathrm{ft}^{2}=11.357 \mathrm{MJ} / \mathrm{m}^{2}$. The base case for each of the qualitative variables ( $H_{1}$ for ACC, $Z_{1}$ for climate zone 1 , and $M_{1}$ for combat flying) are not included in the equation. Note that Eq. 1 also includes interaction terms involving the climate-related variables. Using the stepwise regression technique, with the stipulation that only variables with $p$-values less than 0.05 would be retained, the resulting model was of the form:

$Y=\left[\begin{array}{l}37.903+0.032 X_{1}+0.007 X_{2}- \\ 0.001 X_{1} X_{3}+39.897 H_{3}- \\ 19.288 H_{7}-38.671 Z_{2}- \\ 19.014 Z_{3}-5.250 M_{2}+35.074 M_{4}\end{array}\right](\mathrm{CF})$

where the variables were previously defined. To ensure no misunderstanding though, $X_{1}$ and $X_{2}$ represent the HDD and CDD, respectively; $X_{3}$ is the wind speed; $H_{3}$ and $H_{7}$ indicate that the installation belongs to AFMC and USAFE, respectively; $Z_{2}$ and $Z_{3}$ represent climate zones 2 and 3 , respectively; and $M_{2}$ and $M_{4}$ signify a non-combat flying mission and a strategic/ISR mission, respectively. The $p$-values for the beta coefficients were all less than 0.001 except for the dummy variable associated with non-combat flying, which had a $p$-value of 0.014. The adjusted multiple coefficient of determination, or adjusted $R^{2}$ value, was 0.814 , which means that the model explains $81.4 \%$ of the variability in the data and indicates that the model is a good fit for the data. 
To investigate the correlation or independence of the random error terms associated with the regression equation, we calculated a Durbin-Watson statistic value of 0.532 . Since this value is less than 2 , positive autocorrelation is considered present. In time series data analysis though, such as conducted in this research effort, error terms are commonly positively correlated. This is typically caused by the absence of unknown independent variables, which forces the error terms to include the effects of the missing variables (Kutner et al. 2004). Thus, the variance in the error terms and the true standard deviation of the estimated regression coefficient may be understated; additionally, confidence intervals and tests using the $t$ and $F$ distributions may not be strictly applicable (Kutner et al. 2004). Given these results, we tested for the existence of multicollinearity by calculating the variance inflation factor (VIF) values, which ranged from 1.077 to 5.117 for the independent variables; since the VIF values were less than 10 , multicollinearity was not considered present. Therefore, each regression coefficient was considered stable, indicating the independent variables correlate more with the dependent variable than with each other.

\subsection{Regression analysis discussion}

As Eq. 2 indicates, the final regression model included nine independent variables (three quantitative weather variables and six dummy variables) that proved to have a significant impact on energy consumption at Air Force installations. The base case, shown as the first four terms in the equation, represents an ACC installation in Climate Zone 1 with a combat flying mission. The first term, the constant regression coefficient $\left(\beta_{0}\right)$, corresponds to the non-climatic energy load. Without considering climate-related variables, the energy load for the base case was $430.5 \mathrm{MJ} / \mathrm{m}^{2}$. The only significant weather parameters were outdoor air temperature (in the form of heating and cooling degree-days) and wind speed (in the form of an interaction variable), with changes in these variables affecting the energy consumption to the degree of their regression coefficient values. The regression coefficient was 0.032 for heating degree-days, which means a one unit increase in heating degree-days will increase the energy consumption per square meter by 0.363 when all other variables are held constant. Cooling degree-days has a smaller impact on energy consumption with a regression coefficient of 0.009. Therefore, heating degree-days had the strongest influence on energy consumption, accounting for over $68 \%$ of the variation in energy consumption in terms of contribution to the $\mathrm{R}^{2}$ value, while cooling degree-days accounted for less than $1 \%$. The fact that the coefficients for heating degree-days and cooling-degree days are positive is not surprising as they signify the activation of the respective heating and cooling systems. Of particular interest though was the difference between the HDD and CDD coefficients. The fact that the coefficient for HDD is 4.5 times greater than the CDD coefficient indicates that a degree-day of heating requires 4.5 times more energy than a degree-day of cooling.

The overwhelming significance of heating degree-days in the regression model can be easily explained. The difference between daily mean temperatures and the reference temperature of 18.3 degrees Celsius (65 degrees Fahrenheit) occurs more frequently and in greater quantities for heating degree-days than cooling degree-days. In other words, more heating degree-days are generated since average temperatures throughout the year are more frequently below 18.3 degrees Celsius and at greater ranges than cooling degree-days are above 18.3 degrees Celsius. Therefore, heating requirements outweigh cooling requirements throughout the year, thus increasing its relative influence in predicting energy consumption. This is a well-known fact in the energy discipline that contributed to the initial development of insulation materials and other facility components such as storm windows.

In contrast to heating and cooling degree-days, wind speed and relative humidity individually were not statistically significant to the model; this was somewhat surprising since the literature indicated that both of these weather conditions had proven to be predictive in other studies. For the interaction variable combining heating degree-days and wind speed interaction, its regression coefficient was negative 0.011 . This indicates that a one unit increase of this variable will cause a 0.127 decrease in the energy consumption per square meter when all other variables remain constant. This result was unexpected, especially since the heating degree-day component was included in the interaction term. However, since the regression coefficient was so small, the overall impact was negligible. Furthermore, the interaction variable accounted for only $1.4 \%$ of the variation in energy consumption in terms of contribution to the $\mathrm{R}^{2}$ value.

The addition of dummy variables (i.e., binary variables with values of 0 or 1 ) further refined the model and provided a mechanism to gain addition- 
al insight regarding energy consumption. As previously discussed, ACC, Climate Zone 1, and the Combat Flying mission represented the base case for the regression model. Thus, when interpreting the remaining variables, their contributions to the dependent variable are compared to those of the base case. In the following paragraphs, we attempt to provide possible explanations for the beta coefficients with the caveat that causality was not investigated as part of our research.

Since AETC, AMC, PACAF, and AFSPC were not significant variables, the energy consumption per square meter in these major commands was considered similar to that of ACC. However, installations that are part of AFMC and USAFE use $453.1 \mathrm{MJ} / \mathrm{m}^{2}$ more energy and $219.1 \mathrm{MJ} / \mathrm{m}^{2}$ less energy, respectively, than ACC installations. A possible reason for the additional energy use by AFMC installations may be the depot maintenance activities occurring on aircraft, as well as the presence of numerous research laboratories. The magnitude of activity associated with overhaul operations on aircraft may be energy intensive; additionally, the specialized equipment used during research activities may have unique power requirements. As for the USAFE installations, which are all located in Europe, a possible explanation for lower energy consumption may be a combination of the climate and the fact that the facilities are more basic with fewer overall power requirements. Additionally, the presence of a local foreign national workforce on USAFE installations may contribute to an increased appreciation for environmental issues.

Climate Zone 2 (CZ2) and CZ3 both had negative coefficients, indicating that installations in these zones use 439.2 and $215.9 \mathrm{MJ} / \mathrm{m}^{2}$ less energy, respectively, than installations in CZ1. It is important to note that CZ1 consists of northern tier states, as shown earlier in Figure 2, with a high number of heating degree-days and a minimal requirement for cooling systems. Since the states in CZ2 and CZ3 are south of CZ1, it was not surprising to see that installations in these climate zones use less energy. However, since CZ3 is south of CZ2, it was somewhat surprising to discover that installations in CZ3 typically use 223.2 MJ/m² more energy than installation in CZ2. Therefore, it appears that as the heating requirements decline, the need for cooling systems begins to increase. This may also help explain why CZ4 and CZ5 were not significant, which implies that energy consumption rates in these climate zones were similar to that of $\mathrm{CZ} 1$.
In terms of mission type, installations with a Non-Combat Flying and Strategic/ISR mission use $59.6 \mathrm{MJ} / \mathrm{m}^{2}$ less energy and $398.3 \mathrm{MJ} / \mathrm{m}^{2}$ more energy, respectively, than installations with a Combat Flying mission. Installations with a noncombat flying mission tend to have a lower level of activity, which helps explain why they use slightly less energy. Installations responsible for Strategic/ ISR missions though tend to have more satellite tracking and missile launch capabilities, and the equipment associated with these activities tend to have high electrical requirements. Finally, since the Support mission was not significant, its associated energy consumption per square foot was considered similar to the Combat Flying mission.

Before discussing the trend analysis results, we wanted to examine the model's predictive ability. Recall that one year of data was set aside for final testing of the model. To evaluate the model's performance, we calculated the percentage difference between the actual values and the predicted values from the model. Overall, the mean percentage difference was $20.1 \%$ with a range of 0.6 to $62.1 \%$; furthermore, $23 \%$ of the installations had a percentage differential of less than $10 \%$. Of these installations, 58\% were from Climate Zone 5. Most surprisingly, of the 16 installations with a percentage differential in excess of $30 \%, 81.3 \%$ were of the Combat Flying mission category. For Climate Zone 1, three of the five installations had percentage differentials in excess of $30 \%$. For each of these anomalies, further investigation might provide additional insight to energy policy makers regarding the significant factors impacting energy consumption. For installations with Combat Flying missions for instance, deployments and unusually increased activity may have caused the differences in actual and predicted energy consumption.

\subsection{Trend analysis}

To examine the overall behavior of the dependent variable, we plotted the mean monthly energy consumption data. As shown in Figure 4, the greatest use of energy occurred in January, while the least use occurred in June (closely followed by September). These results were expected in that May/June and September/October are traditionally transition months in which installations are shifting between heating and cooling demands. Commonly, the heating and cooling loads are minimal during this transitional period since the outside air temperature is relatively close to the base or reference temperature of 18.3 degrees Celsius. Additionally, Figure 4 shows that more energy, on 


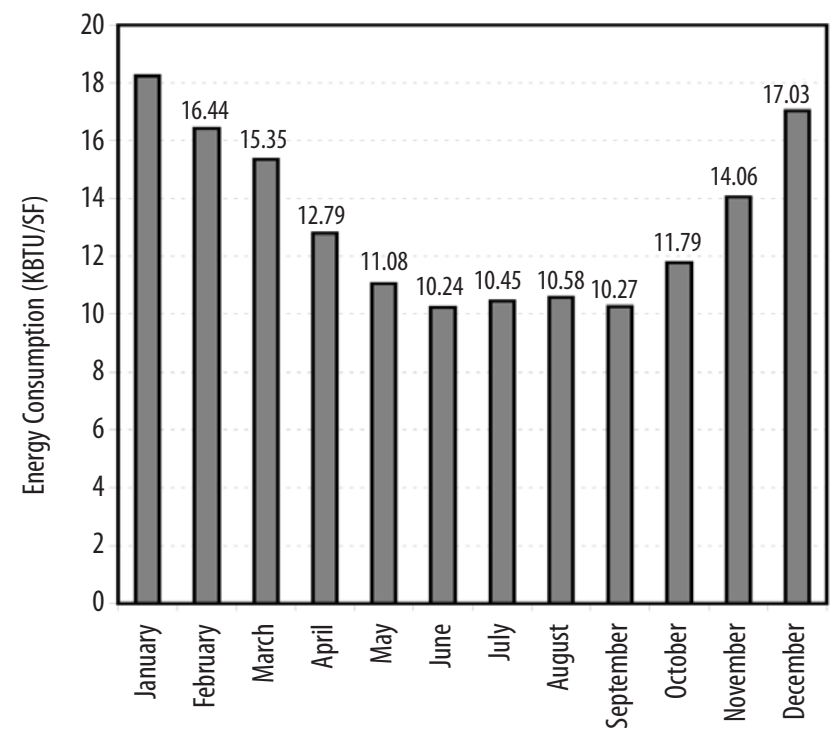

Fig. 4. Mean energy consumption

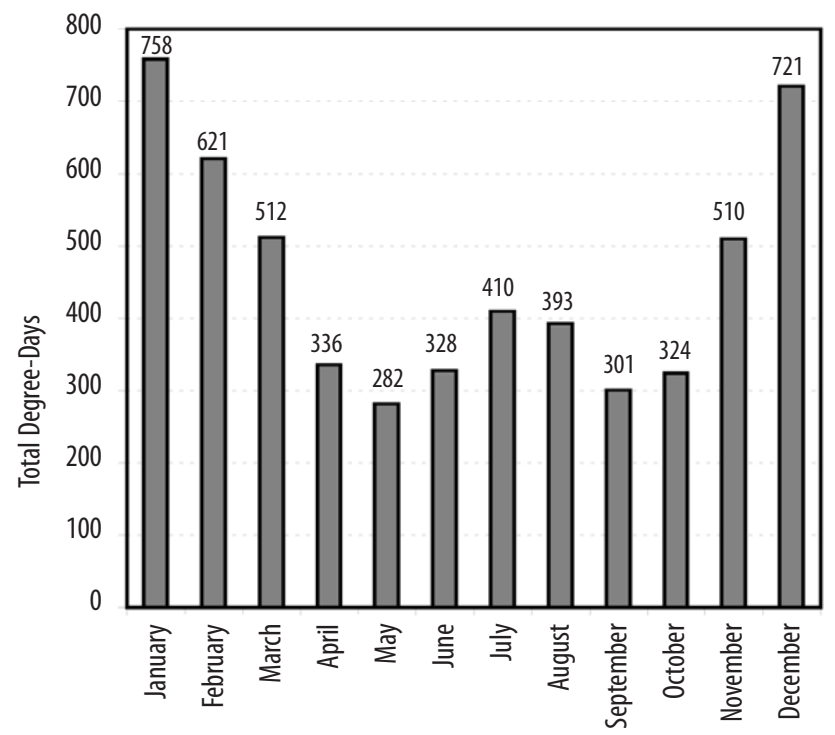

Fig. 5. Monthly mean sum of HDD and CDD

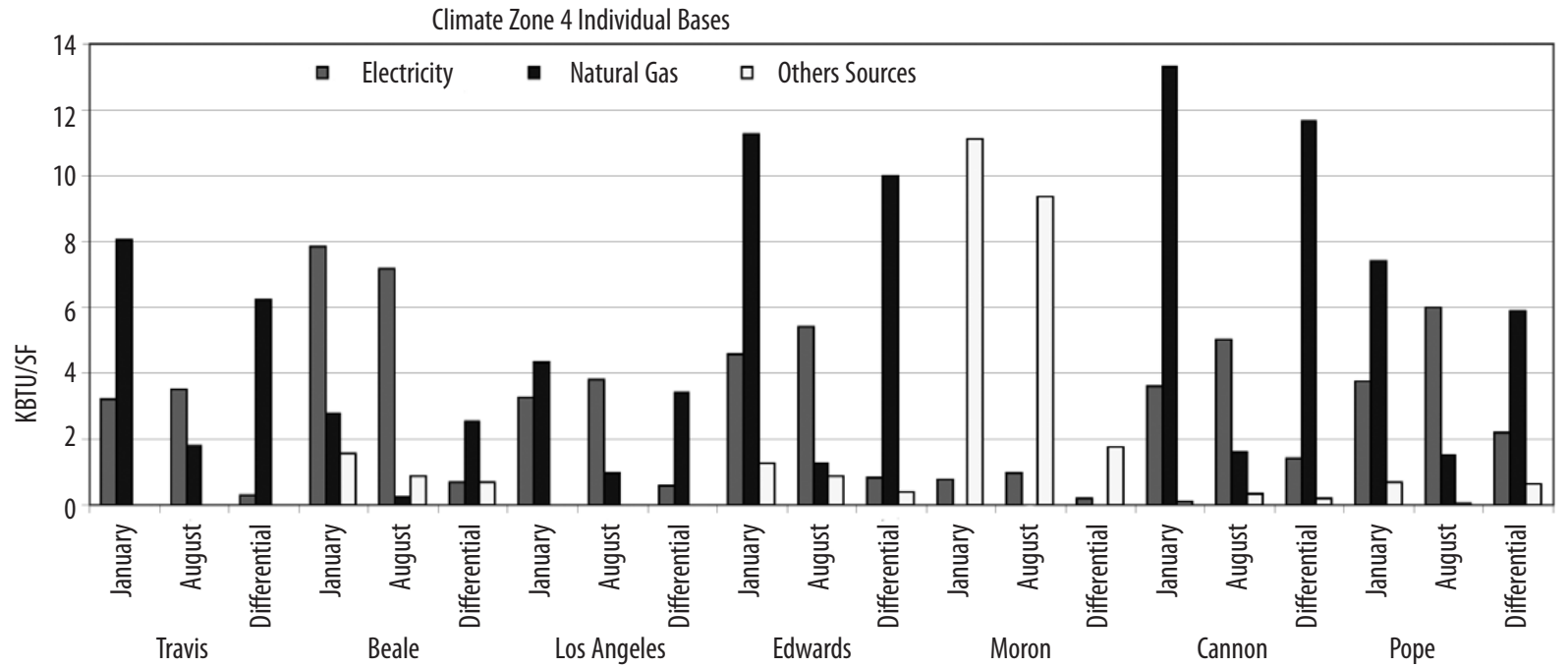

Fig. 6. Energy source consumption in climate zone 4

a square meter basis, appears to be used during the heating season than the cooling season, which is consistent with observations made earlier. To compare this trend to total degree-days, we plotted the mean monthly sums of the HDD and CDD, as shown in Figure 5. Consistent with the energy consumption data, the May/June and September/October timeframes have the lowest mean sum totals of HDD and CDD values. In fact, when comparing the figures, the overall behavior of the respective data is very similar.

To further examine this observation, we plotted each installation's mean energy consumption by source (electricity, natural gas, and other) for January and August, along with the difference between the two months. A representative graph for the installations in Climate Zone 4 is provided as Figure 6. Plotting the data in this manner revealed that the difference in natural gas use between January and August far exceeded the difference in electricity; this was consistent for all climate zones. Of note, the usage difference for the "other" category of energy also exceeded the electricity difference in four of the five climate zones. This was expected since the two predominant energy sources comprising the "other" category were fuel oil and coal, primarily used during the heating season. Thus, natural gas and other fuel sources used during the heating season appear to create a greater opportunity for energy reduction. Additionally, electricity consumption remained relatively stable during both the heating and cooling seasons, especially in the colder climate areas; this suggests that the electrical demand for installations is relatively constant. This further implies that energy conservation initiatives that focus on the electricity used 
for heating and cooling purposes may not have the expected impact. This insight can be of great benefit when developing energy initiative programs.

\section{CONCLUSIONS}

Asset management is all about making more informed decisions to provide desired levels of service based on business principles. A wide range of activities are available to help meet this goal; for instance, a representative list of activities might include leveraging information technology and information management systems, linking project management practices to organizational strategic objectives, implementing business process improvements, etc. Energy management, the focus of our research, is one component of what should be a multi-faceted approach to strategic asset management. Therefore, developing a better understanding of facility energy consumption is a critical step in performing appropriate life-cycle cost analysis studies in the context of broader strategic asset management.

Our research showed that location and mission categories played varying roles in determining energy consumption. Location takes into account the obvious impact of climate. However, considering mission categories helps focus attention on the type of work being performed and its energy intensity. Knowing whether an area is administrative with typical energy requirements or manufacturing-based with greater energy requirements is paramount to decision-makers as they develop policies and programs to target areas consuming the most energy. Therefore, if not already being accomplished, it would be prudent for both energy and facility managers to include the energy intensity for each facility asset in their inventory lists. This type of information could be analyzed at the building, installation/site, or regional level to identify poor performers (in terms of energy consumption), prioritize strategic initiatives, and determine how to optimize resource allocation. Furthermore, our research provides a methodology to predict energy consumption at the installation level to facilitate proactive rather than reactive decision-making.

Although intuitive to some more than others, it is important to note that more energy is used during the winter months than other seasonal periods. Recognition of this difference could affect decisions regarding energy conservation and efficiency efforts, particularly suggesting that more focus should be placed on initiatives targeting heating loads rather than cooling loads. Heating initia- tives would provide the greatest opportunities to reduce overall facility energy consumption, thus helping meet energy reduction goals. However, our analysis does not focus on the costs associated with energy use; since electricity tends to be more expensive than other energy sources, incorporating costs in a life-cycle economic analysis would provide additional insight. In many cases, this may not be an issue since many energy conservation and efficiency initiatives affect both heating and cooling energy consumption. Decision-makers can also assess the potential impact of weather anomalies or suspected climate changes on energy consumption and adjust current directives or policies to compensate for those impacts, such as revising design standards to reflect temperature-related energy use.

Asset management is a structured approach, which is rapidly gain traction throughout the world, to managing real property assets. When determining the capability gap between the assets an organization needs and the assets it owns to perform its mission, energy management is one tool of many to help decision-makers focus on broad strategic asset management activities. Although other energy studies have been reported in the literature, our research is somewhat unique for two reasons. First, we benefitted from the availability of data over a relatively long period of time. Second, our research was presented in the context of asset management. While we believe that others can certainly benefit from the broad insight gained through our research, the true benefit comes from applying our methodology, or one similar to it, and interpreting the results appropriately. The key is to take a holistic perspective as it relates to strategic asset management.

DISCLAIMER. The views expressed in this paper are those of the authors and do not reflect the official policy or position of the United States Air Force, Department of Defense, or the United States government.

\section{REFERENCES}

DoD. 2011. Annual energy management report fiscal year 2010 [online]. U.S. Department of Defense (DoD). Available at: http://www.acq.osd.mil/ie/energy/DoD_ AEMR_FY2010_July_2011\%5B1\%5D\%5B1\%5D.pdf [accessed 23 April 2012]

DOE. 2011a. Annual energy review 2010. Document DOE/EIA-0384(2010) [online] Energy Information Administration, U.S. Department of Energy (DOE). Available at: http://www.eia.gov/totalenergy/data/annual/archive/038410.pdf [accessed 15 March 2012] 
DOE. 2011b. International energy outlook 2011. Document DOE/EIA-0484(2011) [online]. Energy Information Administration, U.S. Department of Energy (DOE). Available at: http://www.eia.gov/forecasts/ archive/ieo11/pdf/0484(2011).pdf [accessed 15 March 2012]

EIA. 2012. U.S. Climate Zones for 2003 CBECS [online]. Energy Information Administration (EIA), U.S. Department of Energy. Available at: http:// www.eia.gov/consumption/commercial/census-maps. cfm\#2003climate [accessed 23 April 2012]

Eto, J. H. 1988. On using degree-days to account for the effects of weather on annual energy use in office buildings, Energy and Buildings 12(2): 113-127. http://dx.doi.org/10.1016/0378-7788(88)90073-4

Executive Order 12893. 1994. Principles for federal infrastructure investments, The White House.

Federal Highway Administration. 1999. Asset management primer, U.S. Department of Transportation.

Federal Highway Administration. 2010. AASHTO transportation asset management guide: a focus on implementation, U.S. Department of Transportation.

Forth, J. B.; Tobin, T. 2004. Enterprise energy management, Buildings 98(8): 18.

Guerre, J. A.; Robert, W. E.; Bradbury, A.; Goodale, M. 2005. The executive support system of Ontario, Canada: integrating pavement and bridge management systems, Transportation Research Record 1933: 27-34. http://dx.doi.org/10.3141/1933-04

Kutner, M. H.; Nachtsheim, C. J.; Neter, J. 2004. Applied linear regression models. $4^{\text {th }}$ Ed. McGraw-Hill Companies Higher Education Press.

Lam, J. C. 1998. Climatic and economic influences on residential electricity consumption, Energy Conversion and Management 39(7): 623-629. http://dx.doi. org/10.1016/S0196-8904(97)10008-5

Lavy, S.; Shohet, I. M. 2010. Performance-based facility management - an integrated approach, International Journal of Facility Management 1(1): 1-14.

Le Comte, D. M.; Warren, H. E. 1981. Modeling the impact of summer temperatures on national electricity consumption, Journal of Applied Meteorology 20(12): 1415-1419. http://dx.doi.org/10.1175/15200450(1981)020<1415:MTIOST>2.0.CO;2

McClave, J. T.; Benson, P. G.; Sincich, T. 2005. Statistics for business and economics. $9^{\text {th }}$ Ed. Pearson Prentice Hall.

Mirasgedis, S.; Sarafidis, Y.; Georgopoulou, E.; Lalas, D. P.; Moschovits, M.; Karagiannis, F.; Papakonstantinou, D. 2006. Models for mid-term electricity demand forecasting incorporating weather influences, Energy 31(2-3): 208-227. http://dx.doi. org/10.1016/j.energy.2005.02.016

National Resource Council. 2004. Investments in federal facilities: asset management strategies for the $21^{\text {st }}$ century. Washington, DC: The National Academies Press.

National Research Council. 2008. Core competencies for federal facilities asset management through 2020: transformational strategies. Washington, DC: The National Academies Press.
Okoroh, M. I.; Jones, C. M.; Ilozor, B. D. 2003. Adding value to constructed facilities: facilities management hospitality case study, Journal of Performance of Constructed Facilities 17(1): 24-33. http://dx.doi. org/10.1061/(ASCE)0887-3828(2003)17:1(24)

Phelps, A. 2011. Municipal property asset management - a comparative study of UK and Russia, International Journal of Strategic Property Management 15(4): 416-437. http://dx.doi.org/10.3846/1648 715X.2011.642537

Price, I. 2004. Business critical FM, Facilities 22(13/14): 353-358. http://dx.doi.org/10.1108/ 02632770410563068

Quayle, R. G.; Diaz, H. F. 1980. Heating degree day data applied to residential heating energy consumption, Journal of Applied Meteorology 19(3): 241-246. http:// dx.doi.org/10.1175/1520-0450(1980)019<0241:HDDD $\mathrm{AT}>2.0 . \mathrm{CO} ; 2$

Rogers, P. A. 2004. Performance matters: how the high performance business unit leverages facilities management effectiveness, Journal of $\mathrm{Fa}$ cilities Management 2(4): 371-381. http://dx.doi. org/10.1108/14725960410808339

Sailor, D. J. 2001. Relating residential and commercial sector electricity loads to climate - evaluating state level sensitivities and vulnerabilities, Energy 26(7): 645-657. http://dx.doi.org/10.1016/S03605442(01)00023-8

Sailor, D. J.; Munoz, J. R. 1997. Sensitivity of electricity and natural gas consumption to climate in the U.S.A. - methodology and results for eight states, Energy 22(10): 987-998. http://dx.doi.org/10.1016/ S0360-5442(97)00034-0

Shohet, I. M. 2006. Key performance indicators for strategic healthcare facilities maintenance, Journal of Construction Engineering and Management 132(4): 345-352. http://dx.doi.org/10.1061/(ASCE)07339364(2006)132:4(345)

Then, D. S. 2003. Integrated resources management structure for facilities provision and management, Journal of Performance of Constructed Facilities 17(1): 34-42. http://dx.doi.org/10.1061/(ASCE)08873828(2003)17:1(34)

Transportation Research Board. 2012. Asset and infrastructure management for airports - primer and guidebook. Washington, National Academy of Science.

Valor, E.; Meneu, V.; Caselles, V. 2001. Daily air temperature and electricity load in Spain, Journal of Applied Meteorology 40(8): 1413-1421. http://dx.doi. org/10.1175/1520-0450(2001)040<1413:DATAEL>2.0 . $\mathrm{CO} ; 2$

Yan, Y. Y. 1998. Climate and residential electricity consumption in Hong Kong, Energy 23(1): 17-20. http:// dx.doi.org/10.1016/S0360-5442(97)00053-4

Yang, L.; Wan, K. K. W.; Li, D. H. W.; Lam, J. C. 2011. A new method to develop typical weather years in different climates for building energy use studies, Energy 36(10): 6121-6129. http://dx.doi.org/10.1016/j. energy.2011.07.053

Yu, Z.; Haghighat, F.; Fung, B. C. M.; Yoshino, H. 2010. A decision tree method for building energy demand modeling, Energy and Buildings 42(10): 1637-1646. http://dx.doi.org/10.1016/j.enbuild.2010.04.006 